\title{
Growth and yield of three sunflower hybrids cultivated for two years under mediterranean conditions
}

\author{
Yolanda Papatheohari', Ilias S. Travlos', Panagiota Papastylianou'1, loannis G. Argyrokastritis², \\ Dimitrios J. Bilalis ${ }^{1}$ \\ ${ }^{1}$ Agricultural University of Athens, Faculty of Crop Science, Laboratory of Agronomy, 75, lera Odos st., 11855 Athens, Greece, ${ }^{2}$ Agricultural \\ University of Athens, Division of Water Resources Management, 75, lera Odos st., 11855 Athens, Greece
}

\section{A B S T R A C T}

\begin{abstract}
Sunflower (Helianthus annuus L.) is globally one of the most important oil crops. A 2-years field study was conducted to evaluate growth, grain and oil productivity of three sunflower hybrids (PR64E83, Oleko and PR63A90). Plant height, number of green leaves, weight of 1000-grains and grain number were significantly affected by the interaction of year and sunflower hybrid. Grain yield resulted to differences ranged among 13 and $34 \%$ between the two years. In 2009, Oleko and PR63A90 were the most productive hybrids regarding seed (8210 and $7500 \mathrm{~kg} / \mathrm{ha}$, respectively) and oil (2960 and $2950 \mathrm{~kg} \mathrm{ha}^{-1}$, respectively), while PR63A90 was the significantly more productive hybrid during the second year (2010). Hybrids such as Oleko seem ideal for high grain and oil yield (with a high concentration of monounsaturated fatty acids); however they fit better to a crop rotation, probably due to a high phytotoxicity of their residues which reduces the yield of the second year. On the contrary, the ability of some non high-oleic hybrids such as PR63A90 to keep high grain yield even in the second year of their cultivation in the same field is clearly a very desirable trait and it should be further tested, since it can result to very high oil yield.
\end{abstract}

Keywords: Sunflower; High-oleic hybrid; Seed oil yield

\section{INTRODUCTION}

Sunflower (Helianthus annus L.) is globally one of the most important arable crops mainly grown for edible oil, due to its high oil content, high non saturated fatty acids content and absence of cholesterol (Leland, 1996; De la Vega and Hall, 2002). Lately, several breeding attempts are towards the direction of the development of sunflower cultivars with high oleic acid concentration (Flagella et al., 2002; Mohammadi et al., 2013). These cultivars are considered to have a high oxidative stability of their oil (Fuller et al., 1967), which is desirable especially for processing and storage. Moreover, a diet rich in monounsaturated fatty acids has many advantages to offer (Grundy, 1986; Delpanque, 2000). In addition, sunflower is not only an important oil crop but is also cultivated for bio-energy purposes such as offering an eco-friendly alternative to diesel fuel (Antolin et al., 2002; Barnwal and Sharma, 2005). In general, it could be said that sunflower is among the most cosmopolitan crops with many uses and high adaptability to diverse envrionments (Beard and Geng, 1982).
In Greece, sunflower is mainly grown in the central and northern part of the country in rotation with plants such as winter cereals and legumes (Kallivroussis et al., 2002). As shown in a worldwide level, many factors such as weeds and water deficit can cause substantial yield losses to sunflower and consequently, the cultivation of the most suitable hybrids is of major importance (Unger, 1990; Breccia et al., 2011). All these factors combined with the specific soil and climatic conditions of each area make the predictions regarding the productivity of each sunflower hybrid even more difficult and the comparative evaluation of several hybrids under the same conditions of major importance, however relative data are rather inadequate.

Therefore, the main objective of the present study was to evaluate - under the same conditions - the growth and productivity (grain and oil yield and oil concentration) of three sunflower hybrids already cultivated in Greece. In particular, this study was conducted in order to see how a high-oleic hybrid grows and yields in comparison with conventional hybrids under low-input conditions.

\footnotetext{
${ }^{*}$ Corresponding author:

Yolanda Papatheohari, Agricultural University of Athens, Faculty of Crop Science, Laboratory of Agronomy, 75, lera Odos st., 11855 Athens, Greece, E-mail: papatheohari@aua.gr
} 


\section{MATERIALS AND METHODS}

\section{Study location}

The field experiment was conducted during 2009 and 2010 in the experimental field of the Agricultural University of Athens ( $\left.37^{\circ} 59^{\prime} 12^{\prime \prime} \mathrm{N}, 23^{\circ} 42^{\prime} 96^{\prime \prime} \mathrm{E}\right)$. Soil was a clay loam (CL), the physicochemical characteristics of which (0- to 15-cm depth increment) were clay $352 \mathrm{~g} / \mathrm{kg}$, silt $457 \mathrm{~g} / \mathrm{kg}$, sand $191 \mathrm{~g} / \mathrm{kg}, \mathrm{pH}\left(1: 2 \mathrm{H}_{2} \mathrm{O}\right) 8.2,1.75 \mathrm{~g} / \mathrm{kg}$ total nitrogen, $0.034 \mathrm{~g} / \mathrm{kg}$ available phosphorus (P-Olsen) and $0.88 \mathrm{~g} / \mathrm{kg}$ available potassium. EC was $2700 \mu$ mhos, $\mathrm{CaCO}_{3} 330 \mathrm{~g} / \mathrm{kg}$ and organic matter content $24.4 \mathrm{~g} / \mathrm{kg}$ (Walkley and Black, 1934). Mean monthly temperature and precipitation data recorded near the experimental area are shown in Table 1.

\section{Experimental details}

Three sunflower hybrids, namely 'PR64E83' (Pioneer), 'Oleko' (Syngenta) and 'PR63A90' (Pioneer) were planted on 27 April 2009 and 4 May 2010. These sunflower hybrids are among the most cultivated ones in Greece, while one of them (Oleko) is known as a high oleic hybrid. They were seeded by hand in $75-\mathrm{cm}$ rows with distances within rows of $20 \mathrm{~cm}$. Before plot establishment each year, $27.5 \mathrm{~kg}$ $\mathrm{N} \mathrm{ha}^{-1}, 16.4 \mathrm{~kg} \mathrm{P} \mathrm{ha}{ }^{-1}$ and $31.3 \mathrm{~kg} \mathrm{~K} \mathrm{ha}^{-1}$ were incorporated with a harrow into the soil (inorganic fertilizer 11:15:15). Plant emergence began 5 days after sowing and was completed within 9 days after sowing.

The experiment was set up on an area of $253 \mathrm{~m}^{2}$ according to the split plot design (randomized complete block) with three replicates and three treatments (sunflower hybrids). The plot size was $5 \mathrm{~m} \times 3 \mathrm{~m}$. The distance among plots was $1 \mathrm{~m}$ and the same distance was also kept among replicates. Weeds were controlled during the growing season by several cultivation and hand-hoeing treatments. Irrigation and other common cultural practices were conducted as needed during the growing seasons. The total water quantity applied was $292 \mathrm{~mm}$ of $\mathrm{H}_{2} \mathrm{O}$.

\section{Measurements}

Five measurements of plant height, number of leaves, leaf area index (LAI), dry weight of leaves, stems and

\begin{tabular}{|c|c|c|c|c|}
\hline \multirow[t]{2}{*}{ Month } & \multicolumn{2}{|c|}{ Rainfall (mm) } & \multicolumn{2}{|c|}{ Temperature $\left({ }^{\circ} \mathrm{C}\right)$} \\
\hline & 2009 & 2010 & 2009 & 2010 \\
\hline March & 80.4 & 11.8 & 12 & 13.4 \\
\hline April & 29.4 & 0.2 & 16 & 17 \\
\hline May & 7.0 & 7.6 & 21.4 & 21.1 \\
\hline June & 0.4 & 15.8 & 25.7 & 25.1 \\
\hline July & 0.8 & 0 & 28.7 & 28.7 \\
\hline August & 0 & 0 & 28.4 & 29.8 \\
\hline Total & 118 & 35.4 & - & - \\
\hline
\end{tabular}

inflorescence (if any) were taken from plants in the three center rows of each plot at 45, 59, 75, 88, 106 and 45, 59, 76, 90, 100 days after sowing (DAS) for 2009 and 2010, respectively. Leaf area was estimated by means of DT-area meter (Delta-T Devices Ltd, Burwell Cambridge, UK), while dry weights were measured after $24 \mathrm{~h}$ at $80^{\circ} \mathrm{C}$ (Miralles et al., 1997). Plots were harvested by hand on 31 August 2009 and 26 August 2010 (127 and 114 DAS, respectively). Yield (grain and oil) was determined and measurements on the stem diameter, seed number and dry weight of 1000 seeds were also taken. Seed moisture at harvest was $5 \%$ as recorded by MT-PRO (Farmex). Moreover, fatty acids were determined according to the internationally accepted methodologies. Oil concentration was determined by means of the crude fat method as proposed by the Association of Official Analytical Chemists (AOAC, 1990). Oil yield was calculated by multiplying seed yields by the concentration of oil in seeds.

\section{Statistical analysis}

Analysis of variance (ANOVA) was conducted for all data and differences between means were separated using Fisher's LSD test at $\mathrm{P}<0.05$. All statistical analyses were conducted using the Statistica 12 software package (StatSoft, Inc. 2300 East 14th Street, Tulsa, OK 74104, USA).

\section{RESULTS AND DISCUSSION}

The analysis of variance of our data revealed that many growth and yield parameters of sunflower were significantly affected by the sunflower hybrid and the year (Table 2). In particular, plant height, number of green leaves, weight of 1000-grains and grain number were significantly affected by the interaction of year and sunflower hybrid. The year on itself was also a significant factor for almost all the crop characteristics, while it had no significant effect on the oil content. Moreover, hybrid's effect was significant for all grain yield and biomass parameters of sunflower (Table 2).

The time course of plant height of sunflower is given in Fig. 1. In general, the time course did not exhibit major fluctuations during the observation period. The height of sunflower plants reached its maximum values at 75 and 88 DAS for 2009 and 2010, respectively. However, it has to be noted that in both years sunflower plants almost doubled their height in the period from 45 to 59 DAS. Moreover, even in most cases there were no significant differences between the three hybrids ( $p>0.05$ ), Oleko was the hybrid with the higher first growth (until 45 DAS) in both years. In general, plant height is considered to be a genetically determined characteristic; however, it is significantly affected by soil and climatic conditions (Pillai et al., 1995). 
Table 2: Analysis of variance for hybrid $(\mathrm{H})$ and year $(\mathrm{Y})$ effects on plant height, number of leaves dry weight of leaves, inflorescences, 1000 seeds, number of seeds and oil content of seeds at harvest

\begin{tabular}{|c|c|c|c|c|c|c|c|c|}
\hline Source & df & $\begin{array}{l}\text { Plant } \\
\text { height }\end{array}$ & $\begin{array}{c}\text { Number of } \\
\text { green leaves }\end{array}$ & $\begin{array}{l}\text { DW of } \\
\text { leaves }\end{array}$ & $\begin{array}{c}\text { DW of } \\
\text { inflorescences }\end{array}$ & $\begin{array}{c}\text { 1000-grain } \\
\text { weight }\end{array}$ & $\begin{array}{l}\text { Number } \\
\text { of grains }\end{array}$ & $\begin{array}{c}\text { Oil } \\
\text { concentration }\end{array}$ \\
\hline$\overline{\mathrm{H}}$ & 2 & $1.83 \mathrm{~ns}^{\dagger}$ & $2.38 \mathrm{~ns}$ & $12.48^{\star * *}$ & $4.79^{* *}$ & $5.36^{* *}$ & $20.18^{\star \star \star *}$ & $0.41 \mathrm{~ns}$ \\
\hline$Y$ & 1 & $21.19^{\star \star \star}$ & $77.51^{\star * *}$ & $7.03^{* *}$ & $52.72^{* \star *}$ & $169.84^{* \star *}$ & $37.29^{\star \star \star}$ & $3.61 \mathrm{~ns}$ \\
\hline $\mathrm{H} \times \mathrm{Y}$ & 2 & $2.35^{\star}$ & $12.01^{* * *}$ & $3.05 \mathrm{~ns}$ & $0.1 \mathrm{~ns}$ & $3.45^{*}$ & $7.38^{* \star *}$ & $1.22 \mathrm{~ns}$ \\
\hline
\end{tabular}

F-test values are shown, ${ }^{*} \mathrm{P}<0.05,{ }^{* *} \mathrm{P}<0.01,{ }^{* \star *} \mathrm{P}<0.001,{ }^{\dagger}$ ns $=$ Not significant
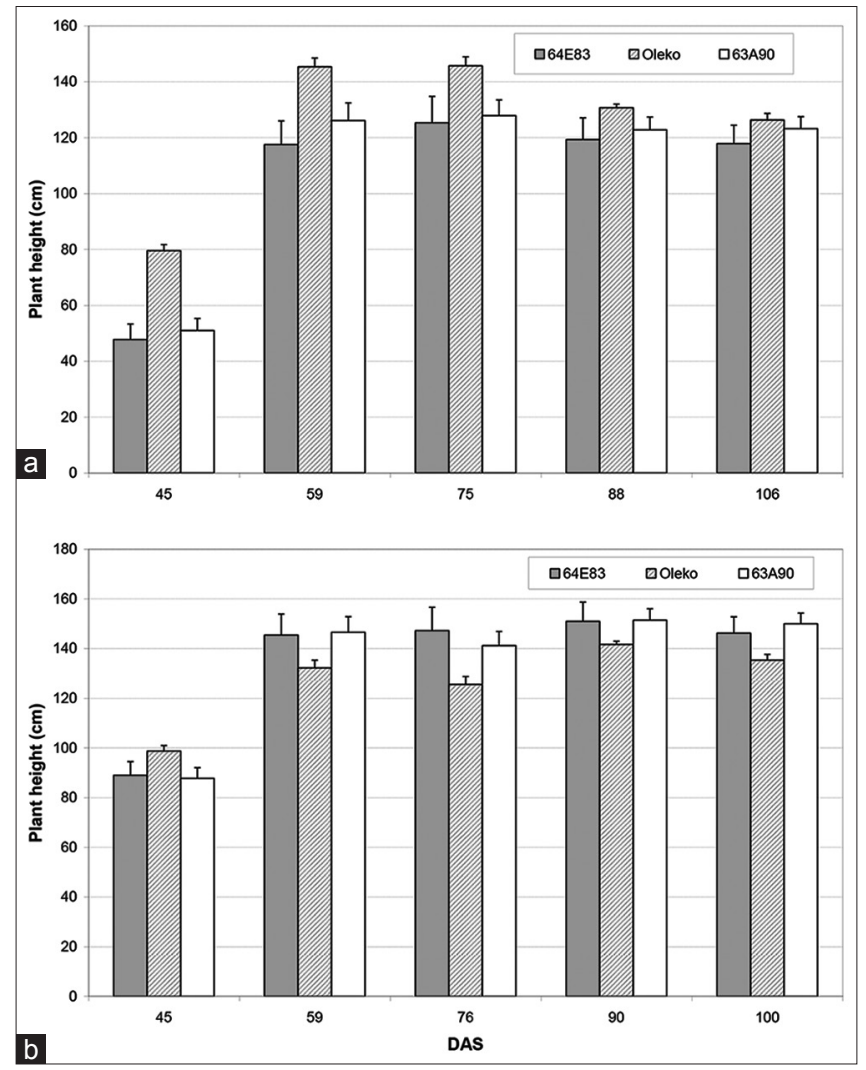

Fig 1. Time course of plant height of the three sunflower hybrids during the two experimental periods ( $\mathrm{a}: 2009$ and b: 2010). Vertical bars denote standard errors of the means.

Vinisree et al. (1998) have shown that higher plants are strongly correlated with higher yields, too. However, this was not true in our case, since the year may play a major role.

Regarding the number of green leaves, there were also some interesting observations (Fig. 2). The rapid early growth of Oleko resulted to a significantly higher leaf number at 45 DAS in 2009, while in 2010 there were not any significant differences during the first growth stages. In addition, from about 75 DAS plants showed a decreasing trend of the number of green leaves, since many of them were in senescence and dried. In the second year, this reduction of the number of green leaves during the last measurement was dramatic, ranging from 80 to $100 \%$ for all three hybrids and may have been due to a combination of water deficit and high air temperatures.

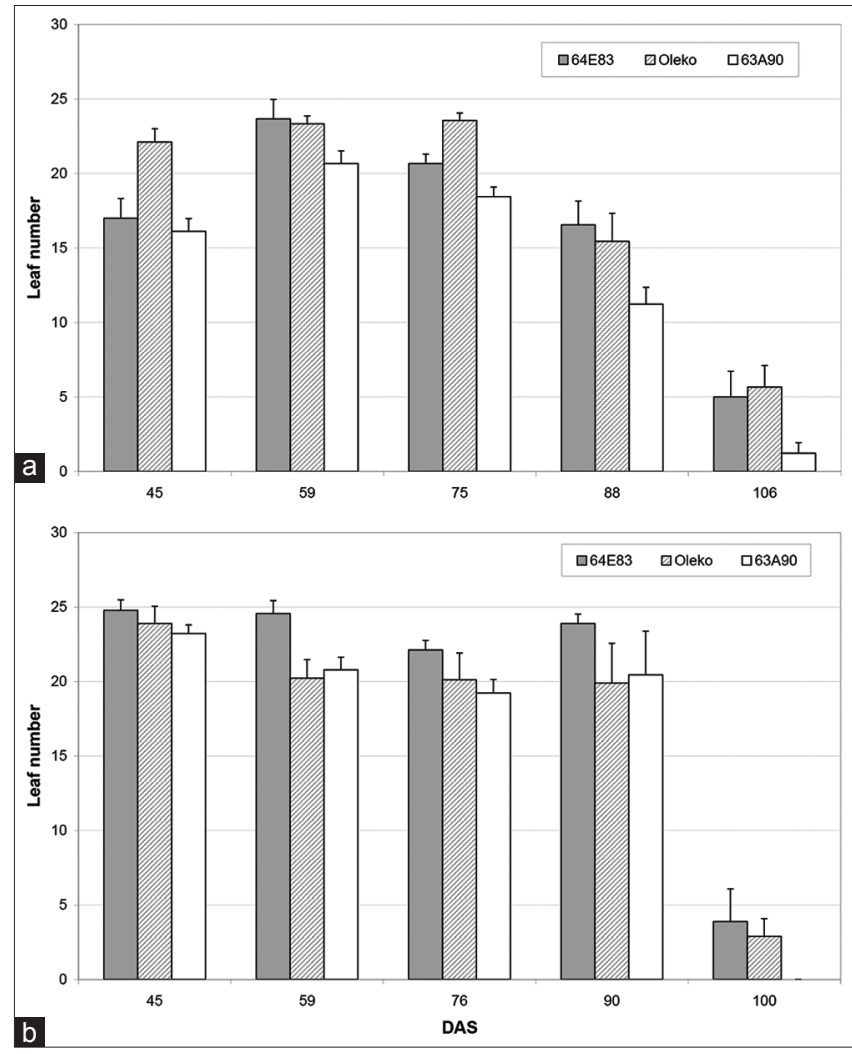

Fig 2. Time course of the number of the green leaves for the three sunflower hybrids during the two experimental periods (a: 2009 and $b: 2010)$. Vertical bars denote standard errors of the means.

In Fig. 3, the time course of LAI is also shown. In 2009, LAI was higher for Oleko in most measurements, while the hybrids PR63A90 and PR64E83 had higher values of LAI than Oleko during the second year. This finding could be attributed to the different response of each hybrid under the different climatic conditions of each year and may be related with differences in the final yields. The time course of the weight of the inflorescences was also rather expected as shown in Fig. 4. However, there was a significant difference among the two years with less grown inflorescences during 2010 compared with the previous year. Another interesting finding has to do with the high values for Oleko hybrid during 2009 and the low values in 2010 compared to the other two hybrids.

The results of the present study have shown some significant differences among years and hybrids regarding yields and yield components. It has to be noted that 


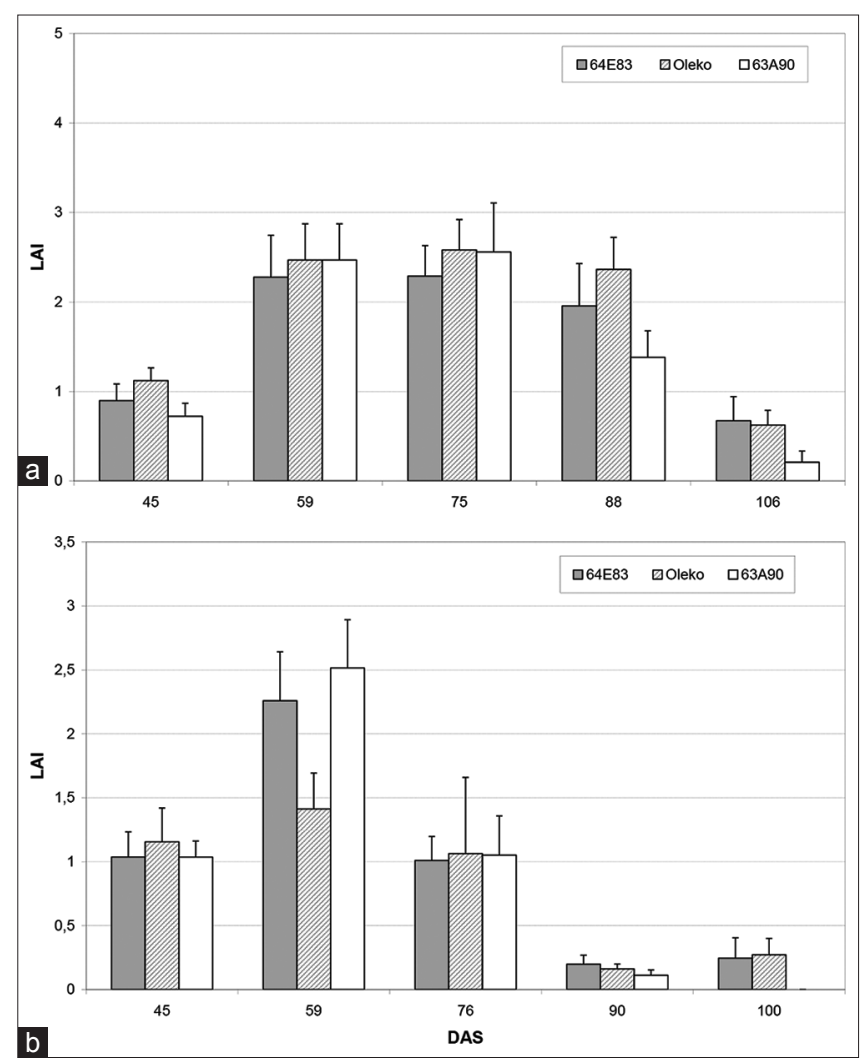

Fig 3. Time course of LAl for the three sunflower hybrids during the two experimental periods (a: 2009 and b: 2010). Vertical bars denote standard errors of the means.

seed yield resulted to differences ranged among 13 and $34 \%$ between the two years (Table 3). There has been a decrease in the yield of 1000-grains in the second year for all these hybrids. This could be mainly attributed to the lower growing season (harvest at 127 and 114 DAS for 2009 and 2010, respectively) and therefore maturity period, too. The significantly lower grain yield of Oleko and PR64E83 in 2010 is certainly related with the lower weight of 1000-grains and the lower grain number per head. Grain formation is intensely affected by temperature and radiation condition during pollination. These results are in full agreement with De la Vega et al. (2002), reporting that the decline of grain number is caused by poor grain formation during late sowing dates which are related with unfavorable environment condition on pollination period. It is well-known that several environmental factors during flowering and seed-filling can significantly affect seed yield (Petcu et al., 2001; Monotti, 2003; Ali et al., 2009). However, even in this case there are some differentiations, due to significant hybrid and year effects and their interactions. In our study, especially in 2010, PR63A90 resulted to a significantly higher yield than the other hybrids (Table 3 ). This different response of each hybrid is clearly related with the genotype and the agronomical characteristics of each hybrid and has been previously reported by Travlos et al. (2014). Oleko and PR64E83 prefer early sowing, while in
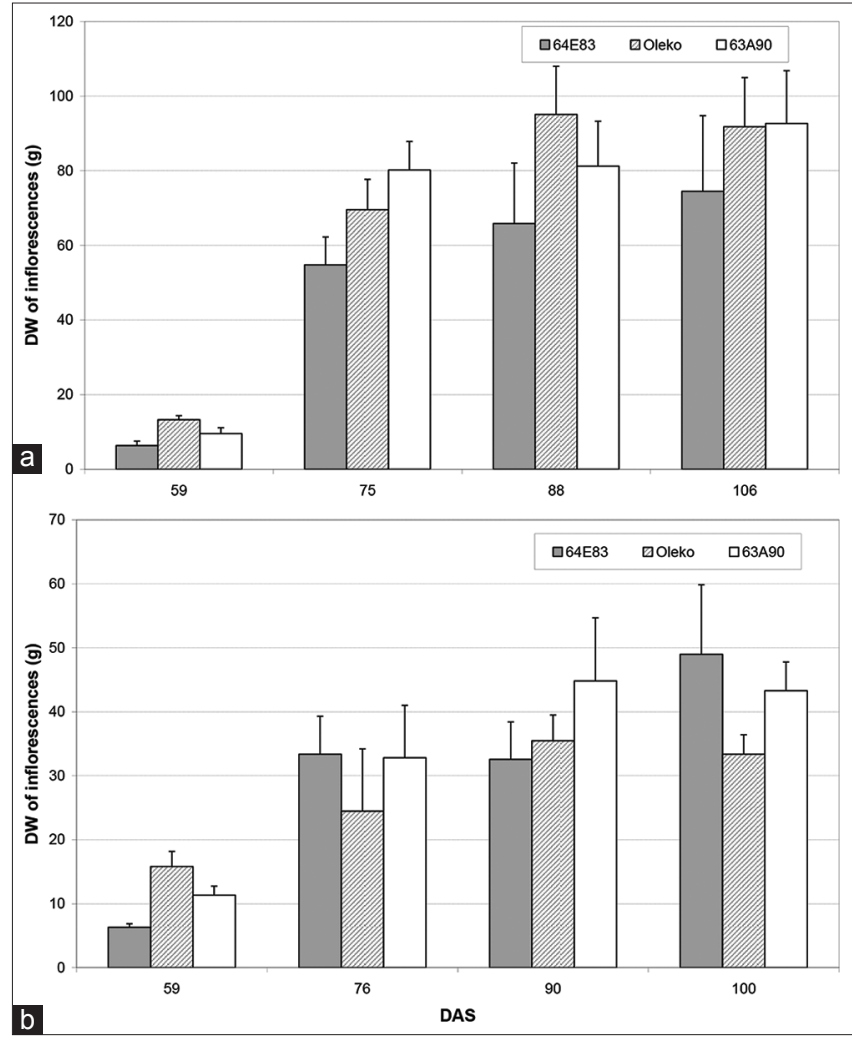

Fig 4. Time course of the dry weight (DW) of the inflorescences for the three sunflower hybrids during the two experimental periods (a: 2009 and b: 2010). Vertical bars denote standard errors of the means.

our study, PR63A90 proved to be more flexible in respect with sowing date.

Moreover, phenomena such as allelopathy may have been involved. It has been observed that sunflower crop has harmful effects on the succeeding crops in multiple cropping systems (Irons and Burnside, 1982; Narwal et al., 1999). Studies have indicated that the harmful effects of sunflower on other plant species were due to allelopathic effects, while it is also a crop that exhibits autotoxicity. Its growing plants inhibit the germination and growth of weeds and succeeding crops due to accumulation of phytotoxins from root exudates and decomposing crop residues (Lovett, 1982; Rawat et al., 2013). Indeed, sunflower contains several compounds like terpenoids and phenolics which are harmful against other plants (Azania et al., 2003; Macías et al., 2004; Anjum and Bajwa, 2005). In a recent study, Dhima et al. (2012) have shown differences between the phytotoxic activity of six sunflower hybrids and their residues effects on succeeding weeds and crops. It has to be noted that in both years of their study, PR64E83 was consistently the hybrid that resulted to a lower fresh weight of ivy-leaved speedwell (Veronica bederifolia L.). That indicates a strong phytotoxic action by means of the crop residues of the specific hybrid and this autotoxicity is probably among the main reasons for 
Papatheohari, et al.: Evaluation of growth and yield of sunflower hybrid

Table 3: Yield and yield components of the three sunflower hybrids during the two years of experimentation

\begin{tabular}{llccccc}
\hline Year & Hybrid & Grain yield $\left(\mathbf{k g ~ h a}^{-1}\right)$ & $\mathbf{1 0 0 0}$-grain yield $\mathbf{( g )}$ & Grain number per head & Oil concentration $(\%)$ & Oil yield $\left(\mathbf{k g}\right.$ ha $\left.{ }^{-1}\right)$ \\
\hline 2009 & PR64E83 & $6680 \mathrm{~cd}$ & $72.32 \mathrm{a}$ & $1330.82 \mathrm{a}$ & $37.30 \mathrm{ab}$ & $2380 \mathrm{~b}$ \\
& Oleko & $8210 \mathrm{~b}$ & $77.71 \mathrm{a}$ & $1492.11 \mathrm{a}$ & $36.27 \mathrm{ab}$ & $2960 \mathrm{a}$ \\
& PR63A90 & $7500 \mathrm{bc}$ & $61.70 \mathrm{~b}$ & $1617.04 \mathrm{a}$ & $38.77 \mathrm{a}$ & $2950 \mathrm{a}$ \\
2010 & PR64E83 & $5820 \mathrm{de}$ & $40.26 \mathrm{c}$ & $832.07 \mathrm{~b}$ & $36.27 \mathrm{ab}$ & 2220bc \\
& Oleko & $5200 \mathrm{e}$ & $42.46 \mathrm{c}$ & $761.04 \mathrm{~b}$ & $34.03 \mathrm{bc}$ & 1770c \\
& PR63A90 & $9910 \mathrm{a}$ & $40.38 \mathrm{c}$ & $1545.19 \mathrm{a}$ & $30.50 \mathrm{c}$ & $3020 \mathrm{a}$ \\
\hline
\end{tabular}

Mean values within the same column followed by the same letter(s) are not significantly different using LSD tests at $P=0.05$

Table 4: Profile of fats (\% of main fatty acids) of the three sunflower hybrids during the two years of experimentation

\begin{tabular}{|c|c|c|c|c|c|c|c|c|}
\hline \multirow[t]{2}{*}{ Year } & \multirow[t]{2}{*}{ Hybrid } & \multicolumn{7}{|c|}{ Percentage of fatty acids } \\
\hline & & Saturated & Monounsaturated & Polyunsaturated & Palmitic & Steatic & Elaic cis & Linelaic cis \\
\hline \multirow[t]{3}{*}{2009} & PR64E83 & $20.03 a$ & $60.14 b$ & $19.82 \mathrm{~b}$ & $11.79 a$ & $5.9 a$ & $58.25 b$ & $19.72 b$ \\
\hline & Oleko & $8.89 c$ & $86.67 a$ & $4.44 \mathrm{c}$ & $4.57 d$ & $3.02 b$ & $86.07 a$ & $4.34 \mathrm{c}$ \\
\hline & PR63A90 & $18.85 a$ & $64.83 b$ & $16.33 b$ & $11.55 a$ & $4.82 a$ & $62.93 b$ & $16.2 b$ \\
\hline \multirow[t]{3}{*}{2010} & PR64E83 & $10.85 \mathrm{bc}$ & $41.77 \mathrm{c}$ & $47.38 a$ & $6.69 \mathrm{bc}$ & $3.25 b$ & $40.32 b$ & $47.2 a$ \\
\hline & Oleko & $8.88 \mathrm{c}$ & $83.81 a$ & 7.31c & $5.08 \mathrm{~cd}$ & $2.88 b$ & $82.19 a$ & $7.22 \mathrm{c}$ \\
\hline & PR63A90 & $12.14 b$ & $43.34 \mathrm{c}$ & $44.53 a$ & $7.69 b$ & $3.32 b$ & $41.69 c$ & $44.36 a$ \\
\hline
\end{tabular}

Mean values within the same column followed by the same letter(s) are not significantly different using LSD tests at $\mathrm{P}=0.05$

the significantly lower grain yield of PR64E83 in 2010, as shown in Table 3. This could be also true for Oleko, but not for PR63A90. The number of grains for PR63A90 was higher during 2010 (resulting to high grain yield), probably because of a lower phytotoxic action of the residues of this specific hybrid, combined with the higher rainfall during June 2010 compared with the previous year (period of seed formulation).

Oil content of sunflower is known to be affected by the hybrid and the temperature during seed development (Canvin, 1965; Skoric, 1992). According to Robertson et al. (1971), high oleic hybrids have usually oil content of $32.2-44.3 \%$, while the corresponding values for conventionally hybrids were $23.4-33.4 \%$. In our study, the high concentration of elaic acid in Oleko is rather anticipated (Skoric, 1992), however, the high concentration in 63A90 was probably due to cross pollination and the insects previously visited the high oleic hybrid (Table 4). Genotype is considered as the main factor that determines the oleic acid concentration as previously suggested by Fernandez et al. (1989) and Izquierdo et al. (2002), however, cross pollination by honeybees can affect the grain yield and oil content (Nderitu et al., 2008). Moreover, the high temperatures during grain filling until maturity may have also played an important role to the high values observed (Robertson et al., 1971; Anderson et al., 1978; Hazel et al., 1978).

Our study also revealed some significant correlations among the several growth and yield parameters of sunflower. For 2009, LAI was strongly correlated with grain and oil yield ( $\mathrm{r}=0.98$ and 0.94 , respectively). This observation is in full accordance with previous studies
(Miralles et al., 1997; Dhima et al., 2012). Moreover, dry weight of sunflower plants was positively correlated with grain and oil yield ( $r=0.95$ and 0.86 , respectively). This finding is in agreements with results of previous studies (Zaffaroni and Schneiter, 1991; Miralles et al., 1997). In addition, dry weight of inflorescences is positively and significantly correlated with dry weight of stems and number of grains ( 0.84 and 0.79 , respectively). Among the several yield parameters, grain number was found to be the one strongly correlated with the final grain yield $(\mathrm{r}=0.92)$, finding that is in full accordance with previous studies, indicating the major importance of this characteristic for final yields (Zaffaroni and Schneiter, 1991). It has also to be noted that there was not any significant correlation between number of grains and weight of 1000 grains $(r=0.49$, ns).

\section{CONCLUSIONS}

The results of the present study indicated that the growth and yield of sunflower hybrids might have a substantial range and should be certainly taken into account for the crop establishment in each region. Similar studies should be continued including more sunflower hybrids, soil and climatic conditions. The ability of some hybrids such as PR63A90, even without being high-oleic, to keep high grain and oil yield even in the second year of their cultivation in the same field is certainly a very desirable trait and it should be further studied. On the other hand, hybrids such as Oleko seem ideal for high grain and oil yield (with a high concentration of monounsaturated fatty acids), however they fit better to a crop rotation, probably due to a high phytotoxicity of the residues (exactly as in the case of PR64E83). Our results highlight the underestimated importance of sunflower hybrid selection for a successful 
establishment of the crop and the overall grain and oil productivity. This is important, especially in agricultural situations and regions where crop rotation is not common or widely adopted by the farmers.

\section{ACKNOWLEDGEMENTS}

Authors would like to thank Filio Moustaferi, Christos Christakis, Evgenios Agathokleous and Kyriakos Christou for their invaluable help with field and experimental activities.

\section{Author's contributions}

The contribution of all authors was equal in this study.

\section{REFERENCES}

Ali, Q., M. Ashraf and F. Anwar. 2009. Physico-chemical attributes of seed oil from drought stressed sunflower (Helianthus annuus L.) plants. Grasas y Aceites. 60: 475-481.

Anderson, W., R. Smith and J. Mc William. 1978. A system approach to the adaptation of sunflower to new environments. I. Phenology and environment. Field Crops Res. 1: 142-152.

Anjum, T. and R. Bajwa. 2005. A bioactive annuionone from sunflower leaves. Phytochemistry. 66(16): 1919-1921.

Antolin, G., F. V. Tinaut, Y. Briceño, V. Castaño, C. Perez and A. I. Ramirez. 2002. Optimisation of biodiesel production by sunflower oil transesterification. Bioresour. Technol. 83: 111-114.

Azania, A. A. P., C. A. M. Azania, P. L. C. Alves, R. Palaniraj, H. S. Kadian, S. C. Sati, L. S. Rawat, D. S. Dahiya and S. S. Narwal. 2003. Allelopathic plants. 7. Sunflower (Helianthus annuus L.). Allelopathy J. 11(1): 1-20.

Barnwall, B. K. and M. P. Sharma. 2005. Prospects of biodiesel production from vegetable oils in India. Renewable sustain. Energy Rev. 9: 363-378.

Beard, B. H. and S. Geng. 1982. Interrelationships of morphological and economic characters of sunflower. Crop Sci. 22: 817-822.

Breccia, G., T. Vega, G. Nestares, M. L. Mayor, R. Zorzoli and L. Picardi. 2011. Rapid test for detection of imidazolinone resistance in sunflower (Helianthus annuus L.). Plant Breed. 130: 109-113.

Canvin, D. T. 1965. The effect of temperature on the oil content and fatty acid composition of the oils from several oilseed crops. Can. J. Bot. 60: 195-200.

De la Vega, A. J. and A. J. Hall. 2002. Effects of planting date, genotype, and their interactions on sunflower yield: I. Determinants of oilcorrected grain yield. Crop Sci. 42: 1191-1201.

Delpanque, B. 2000. Intéret nutritionnel oles tournesols. In: Proceedings of XV International Sunflower Conference, Toulouse, Vol. I. Pp. 15-16.

Dhima, K., I. Vasilakoglou, K. A. Paschalidis, T. Gatsis and R. Keco. 2012. Productivity and phytotoxicity of six sunflower hybrids and their residues effects on rotated lentil and ivy-leaved speedwell. Field Crops Res. 136: 42-51.

Fernandez, J. M., A. Jimenez, J. Dominguez, J. M. Garcia, R. Garces and M. Mancha. 1989. Genetic analysis of the high oleic acid content in cultivated sunflower (Helianthus annuus L.). Euphytica. 41: 39-51.

Flagella, Z., T. Rotunno, E. Tarantino, R. Di Caterina and A. de Caro.
2002. Changes in seed yield and oil fatty acid composition of high oleic sunflower (Helianthus annuus L.) hybrids in rotation to the sowing date and water regime. Eur. J. Agron. 17: 221-230.

Fuller, M., J. Diamond and T. Applewhite. 1967. High oleic sunflower oil. Stability and chemical modification. J. Am. Oil Chem. Soc. 44: 264-267.

Grundy, S. M. 1986. Comparison of monounsaturated fatty acids and carbohydrates for lowering plasma cholesterol. New England J. Med. 314: 745-748.

Hazel, C. H., J. R. Mc William and W. K. Mason. 1978. Influence of temperature on oil content and composition of sunflower seed. Aust. J. Agric. Res. 33: 263-274.

Izquierdo, N., L. Aguirrezabal, F. Andrade and V. Pereyra. 2002. Night temperature affects fatty acid composition in sunflower oil depending on the hybrid and the phenological stage. Field Crops Res. 77: 115-126.

Irons, S. M. and O. C. Burnside. 1982. Competitive and allelopathic effects of sunflower (Helianthus annuus). Weed Sci. 30: 372-377.

Kallivroussis L., A. Natsis and G. Papadakis. 2002. The energy balance of sunflower production for biodiesel in Greece. Biosyst. Eng. 81: 347-354.

Leland, E. F. 1996. Salnity effect on four sunflower hybrids. Agron. J. 88: 215-219.

Lovett, J. V. 1982. Allelopathy and self-defence in plants. Aust. Weeds. 2: 33-36.

Macías, F. A., A. Lopez, R. M. Varela, A. Torres and J. M. G. Molinillo. 2004. Bioactive apocarotenoids annuionones F and G: Structural revision of annuionones A, B and E. Phytochemistry. 65: 3057-3063.

Miralles, O. B., J. A. de Juan Valero and F. M. de Santa Olalla. 1997. Growth, development and yield of five sunflower hybrids. Eur. J. Agron. 6: 47-59.

Mohammadi, K., G. Heidari, M. Javaheri, A. Rokhzadi, M. T. Karim Nezhad, Y. Sohrabi, and R. Talebi. 2013. Fertilization affects the agronomic traits of high oleic sunflower hybrid in different tillage systems. Ind. Crops Prod. 44: 446-451.

Monotti, M. 2003. Growing non-food sunflower in dryland conditions. Ital. J. Agron. 8: 3-8.

Narwal, S. S., T. Singh, J. S. Hooda and M. K. Kathuria. 1999. Allelopathic effects of sunflower on succeeding summer crops. 1. Field observations and bioassays. Allelopathy J. 6: 35-40.

Nderitu, J., G. Nyamasyo, M. Kasina and M. L. Oronje. 2008. Diversity of sunflower pollinators and their effect on seed yield in Makueni District, Eastern Kenya. Span. J. Agric. Res. 6: 271-278.

Petcu, E., A. Arsintescu and D. Stanciu. 2001. The effect of drought stress on fatty acid composition in some Romanian sunflower hybrids. Roman. Agric. Res. 15: 39-43.

Pillai, M. A., P. Ramalingam, C. S. Srodharan, S. Murugan and C. Vanniarajan. 1995. Stability analysis for seed yield and it's components in sunflower hybrids. Ann. Agric. Res. 16: 409-412.

Rawat, L. S., R. K. Maikhuri and V. S. Negi. 2013. Inhibitory effects of leachate from Helianthus annuus on germination and growth of Kharif crops and weeds. Acta Ecologica Sinica 33: 245-252.

Robertson, J. A., J. K. Thomas and D. Burdick. 1971. Chemical composition of the seed of sunflower hybrids and open pollinated varieties. J. Food Sci. 36: 873-876.

Skoric, D. 1992. Achievements and future directions of sunflower breeding. Field Crops Res. 30: 231-270.

Travlos, I. S., D. Bilalis, P. Papastylianou, D. Chachalis, I. Lygizos, I. Annousakis, and Y. Papatheohari. 2014. Response of the growth and yield of sunflower hybrids to organic and inorganic 
fertilization. In: Proceedings of the 13th International Symposium of University of Agricultural Sciences \& Veterinary Medicine ClujNapoca September 2014, Cluj-Napoca. Bull. UASVM Hortic. 71(2): 363-364.

Unger, P. W. 1990. Sunflower. In: Stewart, B.A., Nielson, D.R. (Eds.). Irrigation of Agricultural Crops, ASA Monograph No 30, ASACSSA-SSSA, Madison, WI, Pp. 775-791.

Vinisree, G., K. Ananthasayana, G. S. Nagabhusnanam and C. A.
Jagadish. 1988. Correlation and path coefficient analysis in sunflower. J. Oilseeds Res. 2: 46-51.

Walkley, A. and I. A. Black. 1934. An examination of Degtjareff method for determining soil organic matter and a proposed modifi cation of the chromic acid titration method. Soil Sci. 37: 29-37.

Zaffaroni, E. and A. A. Schneiter. 1991. Sunflower production as influenced by plant type, plant population and row arrangement. Agron. J. 83: 113-118. 